\title{
Response to: Hydroxocobalamin for cobalamin C: which dosage? by V. Wiwanitkit
}

\author{
Nuria Carrillo-Carrasco $\cdot$ Charles P. Venditti
}

Received: 29 January 2010 / Accepted: 6 February 2010 / Published online: 22 June 2010

(C) US Government 2010

To the editor,

Intramuscular hydroxocobalamin $(\mathrm{OHCbl})$ has been used empirically for the management of cblC patients for decades. Its beneficial effects are very clear in the newborn period, with patients achieving metabolic improvement shortly after its initiation. However, the optimal regimens for long-term management of cblC remain undefined and are complicated by the great heterogeneity of this condition. It is common practice to continue patients on the same 1-mg dose of $\mathrm{OHCbl}$ started in the newborn period throughout their lives. Furthermore, several of these patients are weaned from a daily dose to weekly or every other week as they grow older, mainly because of the concerns associated with daily intramuscular injections and the lack of evidence to do otherwise. It is also unclear whether disease-related complications, such as progressive visual loss, are intrinsic to the natural history of the disease or due to sub-optimal metabolic control and can be modified by therapy.

$\mathrm{OHCbl}$ is a medication with few recognized adverse effects. Elevated blood pressure has been reported to occur in a dose-dependent fashion in patients given 5,000 and $10,000 \mathrm{mg}$ of intravenous $\mathrm{OHCbl}$. These doses are 200- to 500-fold above the dose we have used (Uhl et al. 2006, 2008). Whether chronic doses of $25 \mathrm{mg}$ hydroxocobalamin will have a similar effect remains to be determined.

While we agree with Dr. Wiwanitkit in that the results presented in our case report may only represent a short-term

Communicated by: Verena Peters

N. Carrillo-Carrasco $\cdot$ C. P. Venditti $(\bowtie)$

Organic Acid Research Section, Genetics and Molecular Biology

Branch, National Human Genome Research Institute,

National Institutes of Health Building 49, Room 4A18,

Bethesda, MD 20892, USA

e-mail: venditti@mail.nih.gov outcome, we disagree with his contention that "there are some reports on the long term of using $\mathrm{OHCbl}$ and there is no finding that the dose adaptation brings a significant improvement on the outcome". The opposite is suggested by the only report we are aware of that has attempted a dose escalation. Van Hove et al. (2002) demonstrated convincingly that increasing subcutaneous $\mathrm{OHCbl}$ from 1 to $5 \mathrm{mg}$ daily was required to achieve clinical and metabolic control in two patients with cblC and thrombotic microangiopathy. On the other hand, the findings reported by Andersson et al. (1999) suggested cblC is a developmental disorder, not that OHcbl therapy was ineffective. These authors did not attempt dose adaptation studies.

We welcome his comments as they highlight what we have emphasized in our report: a well-planned, long-term clinical trial of higher doses of $\mathrm{OHCbl}$ will be needed to determine whether it is possible to slow or ameliorate cblC disease-related complications.

\section{References}

Andersson HC, Marble M, Shapira E (1999) Long-term outcome in treated combined methylmalonic acidemia and homocystinemia. Genet Med 1:146-150

Uhl W, Nolting A, Golor G, Rost KL, Kovar A (2006) Safety of hydroxocobalamin in healthy volunteers in a randomized, placebo-controlled study. Clin Toxicol (Phila) 44(Suppl 1):1728

Uhl W, Nolting A, Gallemann D, Hecht S, Kovar A (2008) Changes in blood pressure after administration of hydroxocobalamin: relationship to changes in plasma cobalamins-(III) concentrations in healthy volunteers. Clin Toxicol (Phila) 46:551-559, discussion $576-577$

Van Hove JL, Van Damme-Lombaerts R, Grunewald S, Peters H, Van Damme B, Fryns JP, Arnout J, Wevers R, Baumgartner ER, Fowler B (2002) Cobalamin disorder Cbl-C presenting with lateonset thrombotic microangiopathy. Am J Med Genet 111:195201 